\section{Commentary: Axillary or femoral cannulation-Which is the lesser of 2 evils?}

\author{
Koji Takeda, MD, PhD, Serge Kobsa, MD, PhD, \\ Yuji Kaku, MD, and Hiroo Takayama, MD, PhD
}

While arterial cannulation strategy is paramount to success in the management of peripheral venoarterial extracorporeal membrane oxygenation (VA-ECMO), there is wide variability in practice due to a lack of established consensus or guidelines. Peripheral cannulation in femoral or axillary artery is generally preferred over central cannulation in ascending aorta. In this issue of the Journal, Ohira and colleagues ${ }^{1}$ reported their experience with axillary cannulation for VA-ECMO. Including 218 patients receiving axillary cannulation, the study is one of the largest reports of axillary cannulation for VA-ECMO. While this cohort was compared with 153 patients receiving femoral cannulation, the comparative analysis is largely descriptive. Nonetheless, it paints a landscape of the peripheral arterial cannulation strategy and its outcomes at the authors' institution.

Compared with femoral cannulation, axillary cannulation provides antegrade systemic circulation, diminishes upper-body hypoxia related to the mixing cloud, and minimizes aortic root thrombus formation. When combined with internal jugular vein drainage, it can allow ambulatory rehabilitation on VA-ECMO. Axillary cannulation, however, presents a number of challenges. First and most of all, it requires time and expertise, and thus the critical condition of the patient may not allow its application. Hyperperfusion syndrome, only 5 cases $(2.3 \%)$ reported by Ohira and

From the Division of Cardiac, Thoracic and Vascular Surgery, Department of Surgery, Columbia University Irving Medical Center, New York, NY.

Disclosures: The authors reported no conflicts of interest.

The Journal policy requires editors and reviewers to disclose conflicts of interest and to decline handling or reviewing manuscripts for which they may have a conflict of interest. The editors and reviewers of this article have no conflicts of interest.

Received for publication Nov 2, 2020; revisions received Nov 2, 2020; accepted for publication Nov 19, 2020; available ahead of print Dec 7, 2020.

Address for reprints: Hiroo Takayama, MD, PhD, Columbia University Medical Center, Milstein Hospital Building, Suite 7-435, New York, NY 10032 (E-mail: ht2225@cumc.columbia.edu).

JTCVS Techniques 2021;5:74-5

2666-2507

Copyright $(2020$ The Authors. Published by Elsevier Inc. on behalf of The American Association for Thoracic Surgery. This is an open access article under the CC BY-NCND license (http://creativecommons.org/licenses/by-nc-nd/4.0/).

https://doi.org/10.1016/j.xjtc.2020.11.036

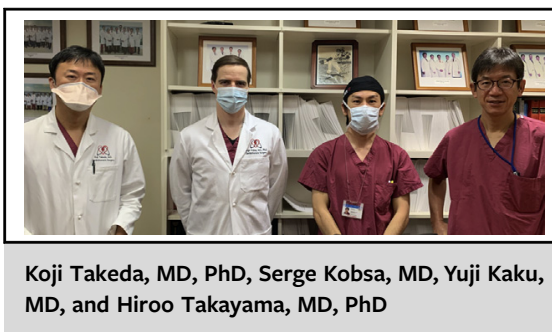

CENTRAL MESSAGE

No cannulation strategy for $V A$ -

ECMO is perfect. Surgeons

should make individualized deci-

sions on the appropriate arterial

cannulation site and revise to an

alternate cannulation site when

required.

colleagues, could be seen up to quarter of all axillary cannulations. $^{2}$ Although the bleeding complication rate was not different between cannulation sites, Ohira and colleagues reported a $15.1 \%$ bleeding rate with axillary cannulation. Anastomotic bleeding or oozing through the graft is frequently seen and is extremely difficult to control once VA-ECMO flow is established. Several tips may help avoid these complications: (1) the graft may be beveled to allow more centrally directed blood flow; (2) distal flow control by axillary artery banding or direct cannulation with distal perfusion can be effective; and (3) use of lower pump flow will reduce pressure on the anastomosis while it may inadvertently compromise end-organ perfusion. Regarding the third point, the authors mentioned in the article that "pump flow of .5-2.2 L/min $/ \mathrm{m}^{2}$ generally provide adequate support, while reducing line pressure"; however, data on organ perfusion were not shown.

Femoral vessels are our first choice. ${ }^{3,4}$ Leg ischemia, a primary concern with femoral cannulation, can be mitigated through placing distal perfusion catheters, using a small arterial cannula, ${ }^{5}$ and monitoring tissue oxygenation in the legs. ${ }^{6}$ Wound complications, another concern with femoral cannulation, might be reduced with percutaneous decannulation techniques using a percutaneous closing device. ${ }^{4,7,8}$

Ohira and colleagues ${ }^{1}$ showed the overall cerebrovascular accident rate did not differ between cannulation sites. This observation is consistent with the unpublished data of our program; however, others reported greater stroke rate with femoral cannulation than axillary. ${ }^{2}$ We have so 
many other issues to discuss, like left ventricular distension, acute renal injury, and anticoagulation strategy, for which this margin is too narrow to contain.

Neither cannulation strategy is perfect. For the time being, we will continue making individualized decisions regarding the most appropriate arterial cannulation site and learn to revise to an alternate site when required. Sometimes sites could be combined.

\section{References}

1. Ohira S, Malekan R, Goldberg JB, Lansman SL, Spielvogel D, Kai M. Axillary artery cannulation for veno-arterial extracorporeal membrane oxygenation support in cardiogenic shock. I Thorac Cardiovasc Surg Tech. 2021:5:62-71.

2. Chamogeorgakis T, Lima B, Shafii AE, Nagpal D, Pokersnik JA, Navia JL, et al. Outcomes of axillary artery side graft cannulation for extracorporeal membrane oxygenation. J Thorac Cardiovasc Surg. 2013;145:1088-92.

3. DeRoo SC, Takayama H, Nemeth S, Garan AR, Kurlansky P, Restaino S, et al. Extracorporeal membrane oxygenation for primary graft dysfunction after heart transplant. J Thorac Cardiovasc Surg. 2019;158:1576-84.e3.
4. Salna M, Takayama H, Garan AR, Kurlansky P, Farr MA, Colombo PC, et al. Incidence and risk factors of groin lymphocele formation after venoarterial extracorporeal membrane oxygenation in cardiogenic shock patients. J Vasc Surg. 2018; $67: 542-8$.

5. Takayama H, Landes E, Truby L, Fujita K, Kirtane AJ, Mongero L, et al. Feasibility of smaller arterial cannulas in venoarterial extracorporeal membrane oxygenation. J Thorac Cardiovasc Surg. 2015;149:1428-33.

6. Patton-Rivera K, Beck J, Fung K, Chan C, Beck M, Takayama H, et al. Using nearinfrared reflectance spectroscopy (NIRS) to assess distal-limb perfusion on venoarterial (V-A) extracorporeal membrane oxygenation (ECMO) patients with femoral cannulation. Perfusion. 2018;33:618-23.

7. Hassan MF, Lawrence M, Lee D, Velazco J, Martin C, Reddy R. Simplified percutaneous VA ECMO decannulation using the MANTA vascular closure device: initial US experience. J Card Surg. 2020;35:217-21.

8. Lüsebrink E, Stremmel C, Stark K, Petzold T, Hein-Rothweiler R, Scherer C, et al Percutaneous decannulation instead of surgical removal for weaning after venoarterial extracorporeal membrane oxygenation-a crossed Perclose ProGlide closure device technique using a hemostasis valve Y connector. Crit Care Explor. 2019;1:e0018.

9. Takeda K, Garan AR, Ando M, Han J, Topkara VK, Kurlansky P, et al. Minimally invasive CentriMag ventricular assist device support integrated with extracorporeal membrane oxygenation in cardiogenic shock patients: a comparison with conventional CentriMag biventricular support configuration. Eur J Cardiothorac Surg. 2017;52:1055-61. 